\section{Ova 15}

ETOPOSIDE IN CISPLATIN-RESISTANT EPITHELIAL OVARIAN CANCER H. Kühnle, W. Achterrath, D. Temme, B. Hinney

Today standard 1st-line therapy of advanced ovarian cancer includes surgical debulking and cisplatin containing chemotherapy regimens with a high response rate of about $80 \%$ but the response rate with any following 2 nd-line therapy is low (Meerpohl, Onkologie 7,22,1984). It was $12 \%$ with Etoposide but the dose was $\leq 50 \%$ of the recommended amount though (Schmoll, Cancer Treatm. Rev. 9,21,1980; Aisner, Cancer Chemother. Pharmacol. 7, 157, 1982). In a phase II studyin patients with primary or secondary resistance to $100 \mathrm{mg} / \mathrm{m}^{2}$ cisplatin we tried to evaluate Etoposide with a modified schedule: $200 \mathrm{mg} / \mathrm{m}^{2} \mathrm{~d} 1-3$ iv. for $2-3$ courses and $300 \mathrm{mg} / \mathrm{m}^{2} \mathrm{~d} 1-3$ or. after that q.4 weekly. The patients' age was 38-79 years (med.61) with a performance status wHO 0-3 (med.1). 42 evaluable patients (until Sept.' 85 ) have been treated with 1-16 courses (med.4). Clinical results: $6 \mathrm{CR}$, 7 PR (CR+PR $31 \%), 17$ NC $(40 \%), 12$ PD. The duration of response (PFI) is CR 7-24+ m, PR 3-17+ m, NC 3-18- m; median PFI for $C R$ and $P R$ has not been reached yet and is $7 \mathrm{~m}$ for $N C$. The average survival for CR is $17,7 \mathrm{~m}$, for $P R 8,4 \mathrm{~m}$ and $10 \mathrm{~m}$ for $\mathrm{NC}$. There were 5 deaths not related to cancer or therapy ( 3 lung embolies, 1 heart failure, 1 bowel perforation) and 1 leukemia after 16 courses in a heavily pretreated patient (alkylating agents). Toxicity: In nearly $50 \%$ the interval had to be lengthened because of the severe but mangeable cumulative haematotoxicity. The $100 \%$ alopecia is mainly a psychological problem. Conclusion: Etoposide given in a higher dose than in previously published phase II studies is an effective agent in patients with primary or secondary resistance against cisplatin. Regarding the quality of life we found that about $50 \%$ of the patients profited from this therapy. The toxicity is tolerable. As 1st-line therapy in combination with cisplatin, Etoposide needs further evaluation in advanced ovarian cancer because the substances are not crossresistant in animal studies (Seeber, pers.comm.).

Universitätsfrauenklinik, 3400 Göttingen, Humboldtallee 19

\section{Ova 16}

THE EVALUATION OF EPIDERMAL GROWTH FACTOR RECEPTORS AS A PROGNOSTIC FACTOR IN ADVANCED OVARIAN CARCINOMAS T. Bauknecht, H.-G.Meerpohl, A-Pfleiderer

Epidermal growth factor receptor (EGF-R), involved in cell growth regulation, is known to be a product of the oncogene erb-B. EGF-R can be detected in human malignant cel]. lines of vulva, cervix and ovary. Recently, we described the occurence and the prognostic value of EGF. $R$ in human ovarian carcinomas. In the meantime the number of $E G F-R$ characterized ovarian carcjnomas could be increased with a prolonged follow-up of these patients.

The content of EGF- $R$ in specimens of ovarian carcinomas was correlated with the response to chemotherapy and the survival time of these patients. Most patients received as a treatment PAC-, PC-combination and the response was controled by second lock surgery if there was no sign of tumor progression. 37 of 103 investigated ovarian carcinomas were EGF-R positive. The histological subtype or tumorrest after primary surgery was nearly equally distributed in EGF-R positive and negative carcinomas. The number of progesteronreceptornegative tumors were slightly increased in the EGF-R positive group. However, in dependence of EGF-R status significant differences in the responserate could be noticed ( $52 \%$ responder in EGF-R positive group, $14 \%$ responder in EGF-R negative group, no evidence of disease was excluded). Additionally, we analyzed the responserates within each treatment regimes. Only small differences in the responserate of EGF-R positive or negative carcinomas could be noticed, if patients were treated by the PAC-com bination. However, significant differences by the PC treat ment was found. We observed no tumor progression in the EGF-R positive group $(n=11), 10 / 17 \mathrm{EGF}-\mathrm{R}$ negative carcinomas showed progressive disease. The median survival time of patients with EGF-R positive carcinomas was 27 months, in the EGF-R negative group 17 months.

These results demonstrate, that the EGF-R status signifies a subgroup of ovarian carcinomas, which have the best treatment results by $P C$ chemotherapy.

Univ.-FrauenkIinik, Hugstetterstr. 55, D 7800 Freiburg

\section{Ova 17}

CYTOSTATIC INHIBITION OF COLONY FORMATION OF OVARIAN CARCINOMA CELLS AND BONE MARROW PROGENITOR CELLS H.M. Runge, H.A. Neumann, K. Braun, A. Pfleiderer

Single cell suspensions from ovarian carcinomas were plated in 30\% fetal calf serum, Iscove's modified Dulbeco's medium and methylcellulose $0,9 \%(w / v)$. As it is difficult to find appropriate in vitro concentrations for the assessment of drug sensitivity, we compared drug sensitivity of tumor cells with that from human bone marrow progenitor Cells (CFU-C), the limiting tissue for cytostatic therapy. Cultures were incubated continuously with Adriamycin, Epirubicin, Cis-Platin, Bleomycin, Peplomycin, Vincristir, Melphalan. In 10 individual tumors out of 35 tests dose response curves could be established for these drugs. In contrast Peplomycin showed a varying inhibition of calony formation from $60-90 \%$ (at $10^{-2}-10 \mu / \mathrm{m} 7$ ) without reduction of bone marrow colonies at these dosages. Te conclude, that the in vitro comparison of malignant and bone marrow cell toxicity might reflect a possible effect of a drug in vivo and might prevent inadequate interpretation when cell killing is obtained in vitro at drug concentrations that are lethal for bone marrow. The comparison of bone marrow and tumor cell toxicity might provide a more precise prediction of sensibility or resistance of a tumor independent of in vivo pharmacologic parameters and drug exposure time.

The inhibition of colony formation by Melphalan and Vincristin indicated no sufficient drug sensitivity. Adriamycin and Epirubicin reduced the colony formation to $40 \%$ $\left(10-5-10^{-} \mathrm{ug} / \mathrm{ml}\right)$ Cis-P atin and B eomycin even to $10 \%$ $(10-2-10 \mu \mathrm{g} / \mathrm{ml})$ of the control cultures, indicating good drug sensitivity. The inhibition of the CFU-C proved to be the same of these effective dosages.

Universitäts-Frauenklinik Freiburg

HugstetterstraBe 55, D-7800 Freiburg

\section{Ova 18}

OVARIAN CARCINOMA: CLINICAL VALIDITY OF SIMULTANEOUS DETERMINATIONS OF VARIOUS TUMOR MARKERS H.G. Schleich, R. Schmidt, I. Hofmann and W.Wiest To evaluate the clinical validity of the combined determinations of tumor markers we measured the activities of 3 markers recommended for ovarian ca (serum ribonuclease activity (SRA), CA 12-5, serum lactate dehydrogenase (LDH). Thresholds were: SRA: 65 ngeqvs RNase A / ml serum, $\mathrm{CA}$ 12-5: $35 \mathrm{U} / \mathrm{ml}$ serum, LDH: $240 \mathrm{mU} / \mathrm{ml}$ serum. Results: Measuring the LDH we found a highly significant difference between the pats with florid ca and the controls (p<0.01). On the contrary, there was no significant difference between the LDH in pats with florid ovarian ca and those clinically without pathological findings after operation and chemotherapy. Also in all cases of increased $\mathrm{LDH}$ we found at least one of the two other markers in the pathologic range. So we concentrated on SRA and CA $12-5$. In 109 pats $(37 \mathrm{ov} . \mathrm{ca}, 11$ ben.ov. tumors, 61 controls) we found for CA $12-5$ a specificity of $100 \%$ and a sensitivity of $70 \%$, for SRA a specificity of $85 \%$ and a sensitivity of $76 \%$. Using the "logistic regression analysis" we find for the coupled determinations of SRA and CA 12-5 a score of $97 \%$ for sensitivity and of $93 \%$ for specificity. The benign ov. tumors were all in the "no ca range" of the test. Prior to a 2nd look laparotomy the SRA and CA $12-5$ levels were measured in 8 pats. Both markers were normal in 1 pat without detectable tumor residues. In the other 7 pats with confirmed tumor residues at least 1 marker was increased pathologically. The logistic regression classified all 8 pats correctly.

Universitäts-Frauenklinik, D-6800 Mannheim Theodor-Kutzer-Ufer 